\title{
A Clinical Study On The Influence Of Suture Materials In Oral Wound Healing
}

\author{
Research Article
}

\author{
J.S Thaslima Nandhini ${ }^{1}$, P. Senthil Murugan ${ }^{2}$, M. Jeevitha ${ }^{3}$
}

${ }^{1}$ Saveetha Dental College And Hospitals, Saveetha Institute Of Medical and Technical Sciences, Saveetha University, Chennai,600050, India. ${ }^{2}$ Associate Professor, Department of Oral and Maxillofacial Surgery, Saveetha Dental College and Hospitals, Saveetha Institute Of Medical And Technical Sciences, Saveetha University, Chennai, India.

${ }^{3}$ Senior Lecturer, Department of Periodontics, Saveetha Dental College and Hospitals, Saveetha Institute Of Medical and Technical Science, Saveetha University, Chennai 77, India.

\section{Abstract}

Suture materials play a very important role in healing, reconstruction and reassembly of tissue which got separated due to surgical procedures and trauma, at the same time it promotes healing as well as hemostasis. Suture materials are used in most of the oral surgical procedures and are considered to be most commonly implanted biocompatible materials in the human body. The aim of current study was to evaluate the influence of suturing materials in oral wound healing. We reviewed patient records and analysed the data of 86000 patients between June 2019 and March 2020. In that total of 785 case sheets of extractions were collected and studied. Data envy about suture materials and approval of the ethical committee was taken before the start of the study. Excel tabulation is done. Data were analysed using SPSS statistical software-chi square statistical test. P valve was set as 0.05 as a level of significance.A total of 785 case sheets were reviewed from statistical analysis. Suture materials used in oral wound healing commonly seen in males $(57.5 \%)$. The most common age group seen is $21-35$ years $(69 \%)$. Silk is a commonly $(88.9 \%)$ used suture material. Most of the patients were reviewed $(57.7 \%)$ after the suturing is done. Frequency of surgical site healing is mostly satisfactory in $58.5 \%$.The results of our study showed silk suture material contributes more than polyglactin to faster healing of an oral wound, with fewer incidence of wound dehiscence and milder local reaction.

Keywords: Extraction; Oral Surgery; Postoperative Analysis; Sutures; Wound Healing.

\section{Introduction}

Suture materials play an very important role in healing wounds, which helps in reconstruction and reassembly of tissue separated by a surgical procedure or trauma [1] and at the same time provides hemostasis and wound healing [4]. This location differs from other body sites due to the presence of saliva, high vascularization, specific microbiota as well as its functions related to speech, mastication and swallowing [38]. Suturing is conventional method for approximating wound margins and also suturing may cause permanent suture scars, wound dehiscence, needle prick injuries, foreign body reactions, granulations, ischemia, tissue tearing and various types of infection [35]. Various alternative materials have been used for wound healing since ancient times, ranging from human hair to silk sutures. Although the modern suture materials and techniques are very advanced, intended wound closure still may not be achieved [14].Therefore, there is a need for alternative closure options. The suture can also be known as a strand of material utilized to ligate blood vessels and also approximate tissues [13]. A good understanding of the physiologic process of wound healing is needed to select the suture material which consequently decrease further complications [29]. Suturing is time consuming and requires proper adequate skill [9]. Resorbable sutures must be removed as soon as healing is done because they can act as niders with food lodgements and cause infection to the patient [37]. Besides these, suturing also requires an additional visit for suture removal.

First suture materials were used in ancient Egypt, but significant development occurred in the 1960s and 1970s. First suture mate-

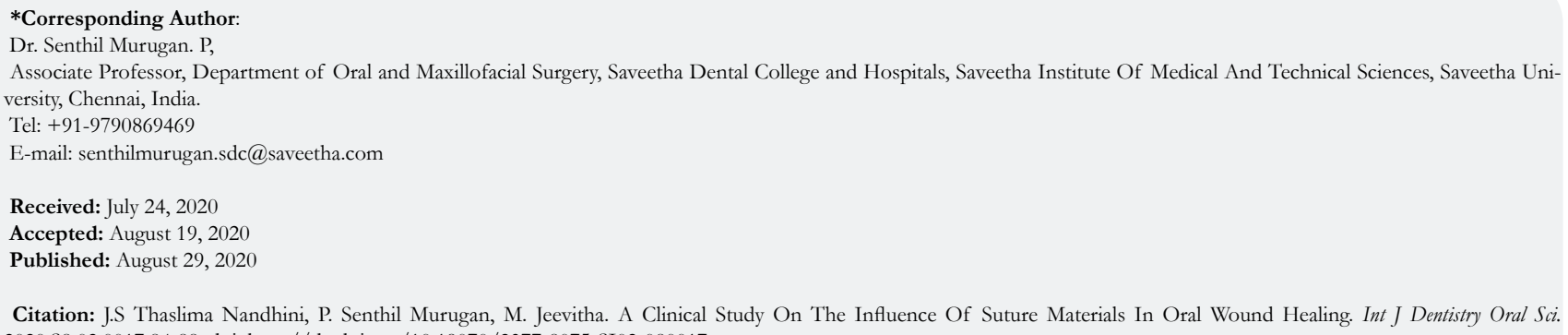

Citation: J.S Thaslima Nandhini, P. Senthil Murugan, M. Jeevitha. A Clinical Study On The Influence Of Suture Materials In Oral Wound Healing. Int J Dentistry Oral Sci. 2020;S8:02:0017:84-88. doi: http://dx.doi.org/10.19070/2377-8075-SI02-080017

Copyright: P. Senthil Murugan ${ }^{\circ} 2020$. This is an open-access article distributed under the terms of the Creative Commons Attribution License, which permits unrestricted use, distribution and reproduction in any medium, provided the original author and source are credited. 
rials made up of a polyvinyl alcohol [7, 31]. Suture materials are widely used in most of the oral surgeries and are considered to be one of the biocompatible substances commonly implanted in our human body. Suture materials are classified based on origin, structure and biological properties. suture materials can be natural or synthetic, monofilament or multifilament, absorbable or nonabsorbable [28]. The main classification is based on biological properties [33] - Natural Absorbable Suture material are Catgut, Collagen, Kangaroo Tendon, Synthetic Absorbable suture material are Dexon, Polyglycolic Acid, Vicryl, Polyglactin. Natural Nonabsorbable Suture Materials are Silk and Cotton, Synthetic Nonabsorbable Suture Materials are Nylon Polypropylene, Polyesters, Polybutester (Novafil). Four basic features of suture materials are knot safety, tissue reactivity, stretch capacity and wound safety. The knot safety shows the capacity of suture materials to retain strength and firmness [36]. Knot safety is reversely proportional to the suture materials, thickness and directly proportional to its quality and functional output [22]. Stretch capacity of suture material is a stretch power capacity per unit area. The wound safety is directly related to the suture capacity that is required for safe healing of the wound [35]. Suture materials in oral and maxillofacial surgery [6] behave differently from those used for other parts of the body due to difference in tissue qualityc [23, 24], presence of saliva, high level of vascularisation and continuous functions like speech, chewing and swallowing [33]. Oral surgery interventions are finished customarily by a surgical suturing of the wound [32]. The choice of suture materials to be used depends on the site and depth of the tissue to stitch [10]. In this type of intervention includes suturing overlying tissue, non absorbable materials are routinely used, which are removed after 5-7 days post operatively. Ideal suture materials not only depend on the biological compatibility and good clinical behavior it also needs features like resistance to traction, dimensional stability, low memory effect, good knot security and good flexibility [5]. The diversity of suture material [38] used in different surgical branches which led to their proper and rationale classification. The silk suture material showed less incidence of alveolar osteitis [20] than other reported studies and also reduced pain [16, 2], inflammation, infection [15] involved in better wound healing [12] . Paracetamol (500mg) [27] and ketorolac(10mg)(19)are the drugs given after dental extractions to reduce pain and infections [17].

There is a lack of information on behaviour of these materials in the oral cavity [26]. Oral environment is characterised by presence of saliva [8], $\mathrm{pH}$ [3], saprophytic bacteria [21]. In spite of modern technologies applied in the production of suturing materials, an ideal suture material is not yet found [18]. Though the lack of an ideal stitch is evident [25], surgical sutures must satisfy some basic criteria for suture material. The aim of the present study is to evaluate the influence of suturing materials in oral wound healing.

\section{Materials and Methods}

This Retrospective study was done in Saveetha Dental College and Hospitals, Chennai, India. We reviewed patient records and analysed the data of 86000 patients between June 2019 and March 2020. Records of the total number of patients who underwent extraction followed by a suturing of the wound were collected and studied. There were both male patients as well as female patients. Approval of the ethical committee was done before starting the study. Ethical approval was obtained from the institutional ethical committee (ethical approval number: SDC/SIHEC/2020/DIASDATA/0619-0320). A total of 785 case sheets were reviewed. These data were cross verified with photographs. Study sampling bias can be minimised by inclusion of all available data. Both Internal and external validity is available. The parameters like age, gender, types of suture materials were analysed, postoperative analysis and surgical site healing records were collected and tabulated. Data was analysed using SPSS statistical software. Descriptive statistics and bi-variant data using chi-square test is done as appropriate. $\mathrm{P}$ value was set as 0.05 as a level of significance.

\section{Results and Discussion}

A Total of 785 case sheets of extractions were reviewed. From the statistical analysis suture material used in oral wounding is most common with male $57.5 \%$ than females $42.5 \%$. The proportion of male is greater than the female. The most commonly seen age group is between $21-35$ years (69\%) Silk is the most commonly used suture material for oral wound healing (88.9\%)compared to polyglactin $(10.2 \%)$. Number of silk sutures used is one $(69.4 \%)$, two (13.9\%). Most of the patients were reviewed (57.7\%) after suturing is done. Patients were reviewedafter 1-2 weeks. Frequency of surgical site healing is mostly satisfactory (58.5\%). Association results values and gender results showed suture materials in oral wound healing have a higher male predilection in its occurrence $57.5 \%$ in males and $42.5 \%$ in females [Figure 1]. In Frequency distribution of the age group of the patients, the most common age group involved is between $21-35$ years $(69 \%)$ other age groups

Figure 1. Bar graph showing comparison between gender and number of suture materials used in closure of oral wound healing. $X$ axis shows gender and $Y$ axis shows count of the patients. Blue colour represents zero suturing done, red colour represents one suture material used and green colour represents two suture materials used. We observed that Gender is not significantly associated with the number of suturing done. Chi square test, $p$ value $0.369(P>0.05$ which is not statistically significant).

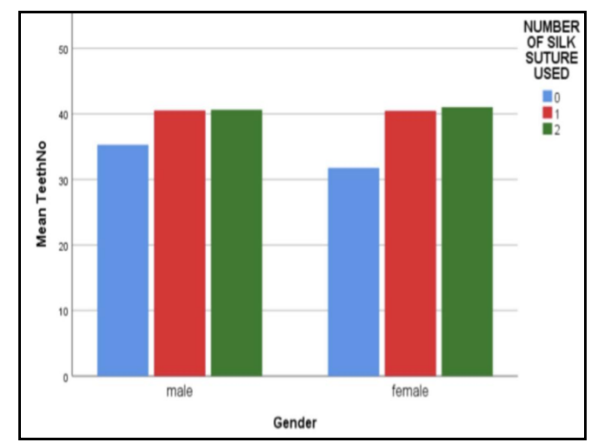


were $12-20$ years $(12.4 \%)$, 36-45 years $(13.3 \%)$, $46-55$ years $(3.3 \%)$, $55-75$ years $(1.78 \%)$ [Figure 2]. In frequency distribution in type of suture material used for closure of oral wound healing, results obtained are silk-(88.9\%), polyglactin- $(10.2 \%)$ and others- $(0.8 \%)$ [Figure 3]. In frequency distribution of patient reviewed or not reviewed, results obtained are patient not reviewed-(42.2\%) and patient reviewed-(57.7\%)[Figure 4]. In frequency distribution of surgical site healing, results obtained are satisfactory heal- ing-(58.5\%) and not satisfactory healing-(41.3\%)[Figure 5]. The choice of the type and size of suture materials depends upon the site and condition of tissue to be sutured. Suture material is a foreign substance implanted into a tissue provoking tissue reaction. In this present study suture material in oral wound healing has a higher male predilection in its occurrence $57.5 \%$ in males and $42.5 \%$ in females. The findings coincide with a study provided by Dejanpelemis et al in 2015 [7], he stated that among 96 cases

Figure 2. Bar graph showing the frequency distribution of age group of the study participants. $\mathrm{X}$ axis shows the patients age in groups and $\mathrm{Y}$ axis shows the number of patients. The most common age group involved in our study is between 21$35(69 \%)$.

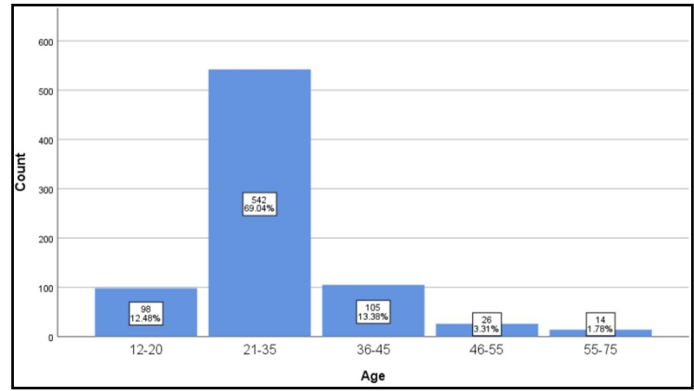

Figure 3. Bar graph showing the frequency distribution of type of suture materials used for closure of oral wound healing. $\mathrm{X}$ axis shows type of suture materials and $\mathrm{Y}$ axis shows number of patients. Patient with silk-88.9\%, polyglactin-10.2\% and other $0.8 \%$. We observed that the silk suture was the most widely used suture material in our study.

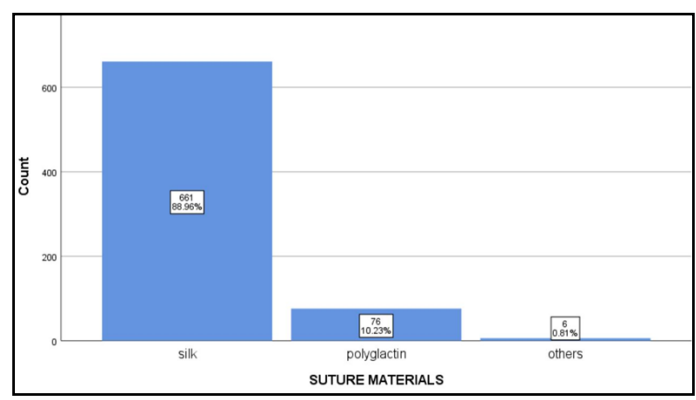

Figure 4. Bar graph showing frequency distribution of patients reviewed or not reviewed. $\mathrm{X}$ axis shows reviewed or not reviewed and $Y$ axis shows number of patients. Percentage of patients reviewed(57.5\%) is higher than the patients not reviewed(42.2\%). In our study we found that the most of the patients turned up for review.

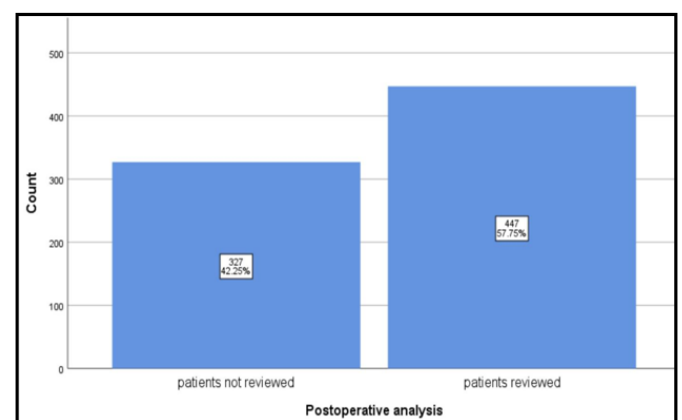

Figure 5. Bar graph showing frequency distribution of surgical site healing. $X$ axis shows satisfactory or not satisfactory healing and $\mathrm{Y}$ axis shows number of patients. Patients with satisfactory healing (58.5\%) are higher than the not satisfactory healing(41.4\%). In our study we found that the most of the patients showed satisfactory wound healing following dental extraction.

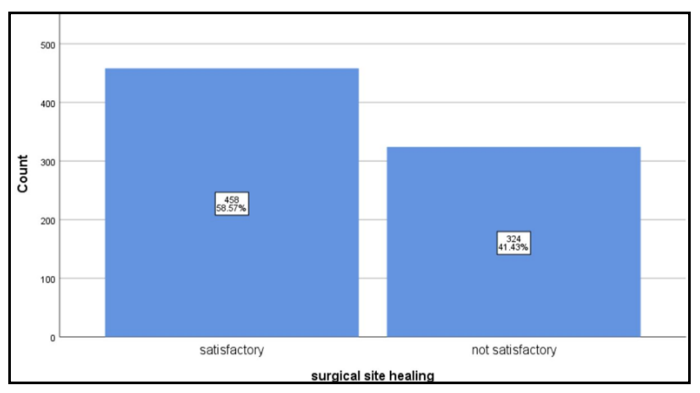


$56.2 \%$ in male and $43.75 \%$ in females. Prevalence of age group, most common is above 30 years $(86.2 \%)$. Sorting $\mathrm{F}$ et al in 2008 [31] stated-majority of the age group seen with an oral wound healing and suture is $9 \%$ to $75 \%$. The possible explanation of this study is the effect of increasing age, loss of alveolar bone, loss of attachment and malnutrition. From the analysis of suture material, silk $(84.2 \%)$ is most commonly used, this contradicts the finding of storch M and scalzo in 2002, [34], they stated vicryl and polyglactin are most commonly used. The possible explanationour study results differ with other articles quoted because of different patient ethnicity and study setting, whereas our study is an institutional study where treatments are done for lower socioeconomic populations.

The results of the study shows most of the patients were reviewed with satisfactory wound healing. This result coincided with the study stated by a Monsour AL et al in 2012 [11], he stated patients have a satisfactory healing with a mild inflammatory reaction and for inflammatory reaction proper medications are given [30]. Reason for limitation of the study is due to the small sample size and area of the study. Future scope of this study is suture material in oral wound healing helps in finding the age, sex, type of suture material used, number of suture materials, post operative analysis and to identify the healing. By knowing all these parameters we can reduce the risk complications and delayed wound healing.

\section{Conclusion}

The results of our study showed that silk is a most common suture material used in study. Silk rapide contributes more than polyglactin to faster healing of oral wounds with fewer inflammatory reactions. Silk is most commonly used because of people's ethnicity and study setting, and moreover economical whereas our study is an institutional study where treatments are done for a lower socioeconomic population that is too free of cost. So from our study we can conclude that silk suture can be safely used in most oral surgical procedures particularly in lower socioeconomic populations because it has better tissue compatibility and is cost effective.

\section{References}

[1]. Abhinav RP, Selvarasu K, Maheswari GU, Taltia AA. The Patterns and Etiology of Maxillofacial Trauma in South India. Ann Maxillofac Surg. 2019 Jan-Jun;9(1):114-117. PubmedPMID: 31293938.

[2]. Sweta VR, Abhinav RP, Ramesh A. Role of Virtual Reality in Pain Perception of Patients Following the Administration of Local Anesthesia. Ann Maxillofac Surg. 2019 Jan-Jun;9(1):110-113. PubmedPMID: 31293937.

[3]. Aderriotis D, Sàndor GK. Outcomes of irradiated polyglactin 910 VicrylRapide fast-absorbing suture in oral and scalp wounds. J Can Dent Assoc. 1999 Jun;65(6):345-7. PubmedPMID: 10412244

[4]. Banche G, Roana J, Mandras N, Amasio M, Gallesio C, Allizond V, et al. Microbial adherence on various intraoral suture materials in patients undergoing dental surgery. J Oral Maxillofac Surg. 2007 Aug;65(8):1503-7. PubmedPMID: 17656275 .

[5]. Bloom BS, Goldberg DJ. Suture material in cosmetic cutaneous surgery. J Cosmet Laser Ther. 2007 Mar;9(1):41-5. PubmedPMID: 17506139.

[6]. Christabel A, Anantanarayanan P, Subash P, Soh CL, Ramanathan M, Muthusekhar MR, et al. Comparison of pterygomaxillarydysjunction with tuberosity separation in isolated Le Fort I osteotomies: a prospective, multi-centre, triple-blind, randomized controlled trial. Int J Oral Maxillofac Surg. 2016 Feb;45(2):180-5. PubmedPMID: 26338075.

[7]. Gazivoda D, Pelemiš D, Vujašković G, Djurdjević S. Influence of suturing material on wound healing - An experimental study on dogs. Vojnosanit Pregl. 2015 May;72(5):397-404. PubmedPMID: 26165046.

[8]. Gazivoda D, Pelemiš D, Vujašković G. A clinical study on the influ- ence of suturing material on oral wound healing. Vojnosanit Pregl. 2015 Sep;72(9):765-9. PubmedPMID: 26554107.

[9]. Ghoreishian M, Gheisari R, Fayazi M. Tissue adhesive and suturing for closure of the surgical wound after removal of impacted mandibular third molars: a comparative study. Oral Surg Oral Med Oral Pathol Oral RadiolEndod. 2009 Jul;108(1):e14-6. PubmedPMID: 19464207.

[10]. Vijayakumar Jain S, Muthusekhar MR, Baig MF, Senthilnathan P, Loganathan S, Abdul Wahab PU, et al. Evaluation of Three-Dimensional Changes in Pharyngeal Airway Following Isolated Lefort One Osteotomy for the Correction of Vertical Maxillary Excess: A Prospective Study. J Maxillofac Oral Surg. 2019 Mar;18(1):139-146. PubmedPMID: 30728705.

[11]. Javed F, Al-Askar M, Almas K, Romanos GE, Al-Hezaimi K. Tissue reactions to various suture materials used in oral surgical interventions. ISRN Dent. 2012;2012:762095. PubmedPMID: 22645688.

[12]. Jesudasan JS, Wahab PU, Sekhar MR. Effectiveness of $0.2 \%$ chlorhexidine gel and a eugenol-based paste on postoperative alveolar osteitis in patients having third molars extracted: a randomised controlled clinical trial. Br J Oral Maxillofac Surg. 2015 Nov;53(9):826-30. PubmedPMID: 26188932.

[13]. Koshak HH. Dental suturing materials and techniques. Global Journal of Otolaryngology. 2017;12(2):1-1.

[14]. Kumar MS, Natta S, Shankar G, Reddy SH, Visalakshi D, Seshiah GV. Comparison between Silk Sutures and Cyanoacrylate Adhesive in Human Mucosa- A Clinical and Histological Study. J Int Oral Health. 2013 Oct;5(5):95-100. Epub 2013 Oct 26. PubmedPMID: 24324311.

[15]. Kumar S. Knowledge, attitude and awareness of dental undergraduate students regarding HIV/AIDS patients ". Asian Journal of Pharmaceutical and Clinical Research. 2017:175.

[16]. Kumar S. Relationship between dental anxiety and pain experience during dental extractions. Asian Journal of Pharmaceutical and Clinical Research. 2017;10(3):458-.

[17]. Kumar $S$. The emerging role of botulinum toxin in the treatment of orofacial disorders: Literature update. Asian Journal of Pharmaceutical and Clinical Research. 2017;10(9):21-9.

[18]. Kumar S, Rahman RE. Knowledge, awareness, and practices regarding biomedical waste management among undergraduate dental students. Asian Journal of Pharmaceutical and Clinical Research. 2017;10(8):341.

[19]. Kumar S, Sneha S. Knowledge and awareness regarding antibiotic prophylaxis for infective endocarditis among undergraduate dental students. Asian Journal of Pharmaceutical and Clinical Research. 2016;154.

[20]. Marimuthu M, Andiappan M, Wahab A, Muthusekhar MR, Balakrishnan A, Shanmugam S. Canonical Wnt pathway gene expression and their clinical correlation in oral squamous cell carcinoma. Indian J Dent Res. 2018 MayJun;29(3):291-297. PubmedPMID: 29900911.

[21]. Okamoto T, Gabrielli MF, Gabrielli MA. Influence of different types of nonresorbable suture material on the healing of extraction wounds--a histological study in rats. J Nihon UnivSch Dent. 1990 Jun;32(2):104-15. PubmedPMID: 2374020.

[22]. Outlaw KK, Vela AR, O'Leary JP. Breaking strength and diameter of absorbable sutures after in vivo exposure in the rat. Am Surg. 1998 Apr;64(4):34854. PubmedPMID: 9544148.

[23]. Packiri S, Gurunathan D, Selvarasu K. Management of Paediatric Oral Ranula: A Systematic Review. J ClinDiagn Res. 2017 Sep;11(9):ZE06-ZE09. PubmedPMID: 29207849.

[24]. Patil SB, Durairaj D, Suresh Kumar G, Karthikeyan D, Pradeep D. Comparison of Extended Nasolabial Flap VersusBuccal Fat Pad Graft in the Surgical Management of Oral Submucous Fibrosis: A Prospective Pilot Study. J Maxillofac Oral Surg. 2017 Sep;16(3):312-321. PubmedPMID: 28717289.

[25]. Patturaja K, Pradeep D. Awareness of Basic Dental Procedure among General Population. Research Journal of Pharmacy and Technology. 2016 Sep $1 ; 9(9): 1349$

[26]. Peterson LJ. Anesthesiology and oral and maxillofacial surgery. Oral Surg Oral Med Oral Pathol Oral RadiolEndod. 2001 Feb;91(2):131-2. PubmedPMID: 11174583.

[27]. Rao TD, Kumar MS. Analgesic efficacy of paracetamolvs ketorolac after dental extractions. Research Journal of Pharmacy and Technology. 2018 Aug $1 ; 11(8): 3375-9$.

[28]. Reed, M. (no date) 'Northumbria Arthroplasty Suture Study (NASS) - A randomised trial comparing standard suture vs. triclosan (antibacterial action) coated suture on rates of surgical site infection', http://isrctn.org/>. doi: $10.1186 /$ isrctn 17807356.

[29]. Sanz L, Smith S. Mechanisms of wound healing, suture material, and wound closure. InStrategies in Gynecologic Surgery 1986 (pp. 53-76). Springer, New York, NY.

[30]. Selvi F, Cakarer S, Can T, KirliTopcu Sİ, Palancioglu A, Keskin B, et al. Effects of different suture materials on tissue healing. J IstanbUnivFac Dent. 2016 Jan 12;50(1):35-42. PubmedPMID: 28955553.

[31]. Sortino F, Lombardo C, Sciacca A. Silk and polyglycolic acid in oral surgery: 
a comparative study. Oral Surg Oral Med Oral Pathol Oral RadiolEndod. 2008 Mar;105(3):e15-8. PubmedPMID: 18280940.

[32]. Stone IK. Suture materials. ClinObstet Gynecol. 1988 Sep;31(3):712-7. PubmedPMID: 3066547.

[33]. Stone IK, von Fraunhofer JA, Masterson BJ. A comparative study of suture materials: chromic gut and chromic gut treated with glycerin. Am J Obstet Gynecol. 1985 Apr 15;151(8):1087-93. PubmedPMID: 3885745.

[34]. Storch M, Scalzo H, Van Lue S, Jacinto G. Physical and functional comparison of Coated VICRYL* Plus Antibacterial Suture (coated polyglactin 910 suture with triclosan) with Coated VICRYL* Suture (coated polyglactin 910 suture). Surg Infect (Larchmt). 2002;3Suppl 1:S65-77. PubmedPMID: 12573041.

[35]. Suthar P, Shah S, Waknis P, Limaye G, Saha A, Sathe P. Comparing intraoral wound healing after alveoloplasty using silk sutures and n-butyl-2-cy- anoacrylate. J Korean Assoc Oral Maxillofac Surg. 2020 Feb;46(1):28-35. PubmedPMID: 32158678 .

[36]. Tera H, Aberg C. Strength of knots in surgery in relation to type of knot, type of suture material and dimension of suture thread. ActaChir Scand. 1977;143(2):75-83. PubmedPMID: 899593.

[37]. Waite PD, Cherala S. Surgical outcomes for suture-less surgery in $366 \mathrm{im}$ pacted third molar patients. J Oral Maxillofac Surg. 2006 Apr;64(4):669-73. PubmedPMID: 16546647.

[38]. Yilmaz N, Inal S, Muğlali M, Güvenç T, Baş B. Effects of polyglecaprone 25, silk and catgut suture materials on oral mucosa wound healing in diabetic rats: an evaluation of nitric oxide dynamics. Med Oral Patol Oral Cir Bucal. 2010 May 1;15(3):e526-30. PubmedPMID: 20038896. 